\title{
KONSEP TAUHID DALAM NASKAH BAHAN AJAR MADRASAH DINIYAH CAMPALAGIAN SEBAGAI MEDIA PEMBELAJARAN AKIDAH
}

\section{Tauhid Concept In the Text of Teaching Material Madrasah Diniyah Campalagian as Learning Media of Aqeedah}

\author{
Syarifuddin * \\ *Balai Litbang Agama Makassar \\ Jl. A.P. Pettarani No. 72 Makassar \\ Email: Svarifuddinamir84@,vahoo.com.
}

Koreksi naskah I tanggal 30 Juli 2012. Koreksi naskah II tanggal 8 Agustus 2012. Finalisasi Naskah 9 Oktober 2012

\begin{abstract}
Abstrak
Penelitian ini membahas tentang Konsep Tauhid dalam Naskah Bahan Ajar Madrasah Diniyah Campalagian (BAMDC). Naskah BAMDC berisi dasar-dasar ajaran Islammeliputi kumpulan-kumpulan hadis, ajaran akidah (tauhid) dan fikih (hukum).Fokus kajian ini yaitu teks tauhid dalam naskah BAMDC dengan mendeskripsikan konsep tauhid dan fungsinya sebagai media pembelajaran akidah. Teks tauhid dalam naskah BAMDC terlebih dahulu diterjemahkan, selanjutnya dianalisis dengan menggunakan teori fungsi teks. Kecamatan Campalagian sebagaipusatpendidikan agama Islam di Polewali Mandar lebih menekankan pada pembelajaran materi tauhid dan fikih yang menjadi ciri khas tersendiri. Tujuannya supaya peserta didik memiliki akidah yang kuat sejak dini. Realitas ini berbeda dengan yang terjadi di daerah lain. Di Pambusuangmisalnya, disampingmateri akidah danfikih,diterapkanpulapembelajaran tarikat dan tasawuf.
\end{abstract}

Keyword: Naskah, Kritik Teks, Tauhid.

\begin{abstract}
This study discusses the concept of tauhid (monotheism) in the Text of Teaching Materials of Diniyah Campalagian (BAMDC). Texts of BAMDC contains the basics Islam teachings include clusters of hadith, the teachings ofaqeedah (tauhid) andfiqh (law). Focus of this study is Tauhid in the text of BAMDC to describe the concept of tauhid and its function as a medium of learning aqeedah. Tauhid in the texts of $B A M D C$ should be first translated, then analyzed by using the theory offunctions of a text. Campalagian sub-district as a center of Islamic religious education in Polewali Mandar more emphasis on learning of Tauhid andfiqh become distinctive characteristics. The goal that the learners have a strong faith early on. The reality is different from what happened in other areas. In Pambusuang for example, in addition to material aqeedah dan fiqh, applied also learning tarekat and mysticism.
\end{abstract}

Keywords: Text, Text Criticism, Tauhid.

\section{PENDAHULUAN}

$\mathrm{K}$ ecamatan Campalagian merupakan salah satu pusat pendidikan agama Islam di Kabupaten Polewali Mandar. Berdasarkan data Kantor Kementerian Agama Polewali Mandar tahun 2010, jumlah lembaga pendidikan agama formal di Kecamatan Campalagian total sebanyak 14 buah yang semuanya berstatus swasta dengan rincian MI sebanyak 7 buah, MTs 5 buah dan MA 3 buah. Jumlah ini merupakan yang terbanyak kedua di Kabupaten
Polewali Mandar setelah Kecamatan Binuang.'Hal ini mengindikasikan bahwa perhatian masyarakat terhadap pendidikan agama daerah ini sangatlah besar. Data ini belum termasuk data lembaga pendidikan non formal seperti Madrasah Diniyah non formal serta pengajian-pengajian kitab yang dilaksanakan di Masjid, rumah-rumah nungguru, dan lain-lain.

Sejak dulu, Campalagian terkenal dengan ciri tradisionalnya. Ini bisa dilihat dari sistem pembelajaran agama Islam melalui Madrasah Diniyah (sikola Arab), 
pengajian pondok serta pengajian kitab kuning dengan materi tertentu yang lokasi berlangsungnya kegiatan belajar mengajar adalah di rumah masing-masing ulama. Materi pembelajaran yang diajarkan berupa Akidah, Fikih, Akhlak dan lainnya. Namun, ketiga materi pokok tersebut (khusunya akidah) lebih ditekankan karena dianggap sebagai bekal yang mendasar untuk mencetak generasi ulama.

Di antara ciri ketradisionalannya lainnya yaitu materi pembelajaran yang digunakan dalam transfer ilmu bukan hanya bersumber dari kitab kuning namun sebagian juga berasal dari tulisan atau catatan guru yang melahirkan sebuah naskah pegangan bagi santri. Berdasarkan realitas tersebut, penelitian ini mengkaji salah naskah Bahan Ajar Madrasah Diniyah Campalagian (selanjutnya disingkat menjadi Naskah BAMDC dengan membatasi pada teks tauhid dengan pertimbangan bahwa materi tauhid merupakan hal pokok dalam ajaran Islam yang harus diketahui terlebih dahulu. ${ }^{2}$ Naskah ini merupakan salah satu naskah keagamaan dari sekian banyak naskah keagamaan yang tersebar di kawasan Indonesia Timur tepatnya di Kecamatan Campalagian Kabupaten Polewali Mandar Sulawesi Barat. Naskah BAMDC secara umum berisi dasar-dasar disiplin ilmu hadis, tauhid dan fikih.

Berdasarkan latar belakang, maka yang menjadi masalah pokok dalam penelitian ini yaitu konsep tauhid dalam naskahbahan ajar Madrasah Diniyah Campalagian sebagai media pembelajaran akidah. Masalah pokok ini kemudian diuraikan ke dalam beberapa rumusan masalah penelitian yaitu: Pertama, Bagaimana kondisi naskah bahan ajar Madrasah Diniyah Campalagian? Kedua, Bagaimana konsep tauhid naskah bahan ajar Madrasah Diniyah Campalagian sebagai media pembelajaran akidah? $d \& n k e t i g a$, Bagaimana fungsi tekstauhidnaskah bahan ajarMadrasah Diniyah Campalagian sebagai media pembelajaran akidah?

Teori yang digunakan dalam penelitian ini yaitu teori filologi dengan mengacu pada analisisdeskripsi dan kritik teks serta teori fungsi teks. Analisis kritiks teks yaitu analisis yang memberikan evaluasi terhadap teks, meneliti dan menempatkan teks pada tempatnya yang tepat. Kegiatan kritiks teks bertujuan menghasilkan teks sedekat-dekatnya dengan teks aslinya. Untuk mencapai tujuan tersebut teks diberikan perbaikan terhadap kesalahan-kesalahan (corrupt) pada teks.

Teks kemudian diterjemahkan dan fungsi teks dianalisis dengan menggunakan teori fungsi teks. Sebuah teks baru disebut referensia atau acuan kalau fungsi utama menyatakan sesuatu atau mengacu pada konteks yang secara umum dibagi kedalam 3 bagian yaitu; teks informatif, teks diskursif dan teks intruksif. ${ }^{4}$ Dalam kajian ini lebih diarahkan pada fungsi teks tauhid naskah BAMDCsebagai teks intruksif yaitu supaya pengetahuan atau keterampilan pembaca secara sistematis diperluas.

Penelitian ini merupakan penelitian kualitatif filologis. Oleh karena penelitian ini bersifat kualitatif, maka pengolahan dan analisis data dilakukan secara kualitatif.Naskah BAMDC sebagai objek kajian merupakan koleksi pribadi H. Mukhtar Hasan di Campalagian Kabupaten Polewali Sulawesi Barat. Data berupa informasi seputar Naskah BAMDC dan teks naskah itu sendiri dideskripsikan secara kodikologi terbatas dan dianalisis dengan analisis kritik teks (tahqiq al-Nushush).Teks naskah kemudian diterjemahkan dengan menggunakan metode terjemahan semantik. Penerjemahan semantik terfokus pada padanan dalam tataran kata dengan tetap terikat pada budaya bahasa sumber. Penerjemahan seperti ini berusaha mengalihkan makna kontekstual bahasa sumber yang sedekat mungkin dengan struktur sintaksis dan semantik bahasa sasaran..$^{5}$ Untuk kelengkapan data, dilakukan wawancara dengan pemilik naskah dalam rangka mendapatkan informasi seputarnaskah serta studi kepustakaan berkaitan studi naskah dan kritik teks.

\section{PEMBAHASAN}

\section{Deskripsi Naskah}

Naskah BAMDC adalah naskah yang berisi dasar-dasar disiplin ilmu meliputi hadis, tauhid dan fikih. Naskah ini merupakan bahan ajar pada lembaga pendidikan Islam non formal di Desa Bonde

\footnotetext{
Naskah pada awalnya tidak memiliki nama, namun karena berdasarkan beberapa pertimbangan terhadap fongsi naskah serta wawancara yang dilakukan dengan pemilik naskah maka naskah ini diberi nama "Naskah Bahan Ajar Madrasah Diniyah Campalagian".

Siti Barorah Baried, et. aX.,Pengantar Teori F//o/og7(Yoyakarta: Badan Penelitian dan dan Publikasi Fakultas Seksi Filologi Fakultas Sastra Universitas Gadjah Mada, 1994), h. 61.

"Partini Sardjono Pradotokusumo. 2001.Pengkajian Sastra..Cet. I; Bandung: Wacan, h. 31. "Rudolf Nababan. 2008. Teori Menerjemah Bahasa Inggris. Cet. I11; Yogyakarta: Pelajar. h.

Rudolf Nababan. 2008. Teori Menerjemah Bahasa Inggris. Cet. Ill; Yogyakarta: Pelajar. h.
} 
Kecamatan Campalagian Kabupaten Polewali Mandar Provinsi Sulawesi Barat. Pemilik naskah ini yaitu $\mathrm{H}$. Muchtar Hasan seorang pensiunan PNS (guru) yang berdomisili di Desa Bonde Kecamatan Campalagian. Naskah ini diwarisi dari almarhum ayahnya $\mathrm{H}$. Muhammad Hasan yang merupakan salah satu perintis berdirinya Madrasah Diniyah di Campalagian. Disamping Naskah BAMDC, ia juga mengoleksi puluhan naskah kuno. Beliau menganggap naskahnaskah tersebut harus dipelihara dan dikaji kembali agar dapat diketahui kandungannya.

Naskah ini diberi judul Naskah (Bahan Ajar Madrasah Diniyah Campalagian) BAMDC. Sebenarnya naskah tersebut tidak memiliki judul dan nomor kode (koleksi pribadi). Namun berdasarkan dari isi naskah tersebut yang memuat dasar-dasar agama Islam meliputi hadis, tauhid dan fikih dan berfungsi sebagai bahan ajar di Madrasah Diniyah Campalagian, maka diberi namaNaskah Bahan Ajar Madrasah Diniyah Campalagian (BAMDC). Pada naskah tidak tercantum nama pengarang dan penulis naskah.

Pada naskah tidak terdapat kolofon namun diperkirakan ditulis sebelum tahun $1323 \mathrm{H}$ sesuai dengan adanya catatan dari pemilik naskah yang ada di bagian terjemah dengan menggunakan bahasa Bugis.Bahasa dan aksara yang digunakan dalam BAMDC adalah bahasa dan aksara Arab dengan jenis tulisan khat naskhi serta catatan terjemahan dalam bahasa Bugis dengan aksara lontara (ditulis dengan pensil).Naskah ditulis pada kertas lokal dengan tinta racikan yang terbuat sari nipa berwarna hitam dengan sampul karton dan plastik.Jumlah halamannya sebanyak 57 halaman dengan 11 baris per halaman (kecuali halaman 15 yang terdiri dari 5 baris dan halaman 57 yang terdiri dari 9 baris).Halaman 1-15 memuat kumpulan hadis, halaman, 16-22 terdiri dari dasar-dasar ilmu tauhid dan halaman 23-57 mencakup ilmu fikih dalam bidang ibadah. Ukuran naskah $16 \mathrm{~cm}$ x $20.5 \mathrm{~cm}$.

Naskah BAMDC ditulis dalam bentuk prosa dengan pola tanyajawab pada teks tauhid dan fikih. Sistem penomoran menggunakan angka Arab yang ditulis pada ujung kanan-kiri naskah. Selanjutnya untuk mempermudah aturan penomoran halaman diberi kata alihan (cathword). Kondisi naskahmasih relatif baik, cukup lengkap dan masih dapat dibaca.Namun pada halaman tertentu terdapat teks yang rusak atau robek sehingga diperlukan ketelitian dalam pembacaannya.

\section{Garis Besar Isi Naskah Bahan Ajar Madrasah Diniyah Campalagian}

Naskah BAMDC terdiri dari 3 bagian.Bagian pertama terdiri dari kumpulan hadis.Dalam naskah disebutkan jumlah hadis sebanyak 40.Namun setelah ditelusuri, jumlah hadis dalam naskah hanya 39 buah.

Bagian kedua terdiri dari disiplin ilmu tauhid versi Asy'ariyah. Pada bagian ini terdiri dari:

1. S ifat-sifat Allah swt yang meliputi sifat waj ib bagi Allah swt 20 sifat, sifat mustahil bagi Allah sebanyak 20 sifat dan satu sifat jaiz bagi Allah swt.

2. Sifat-sifat Rasul-rasul Allah swt yang meliputi sifat wajib 4 sifat, sifat mustahil 4 sifat dan satu sifat jaiz.

3. Rasul-rasul yang waj ib diketahui oleh orang yang beriman. Bab ini terdiri dari jumlah rasul sebanyak 25 yang wajib diketahui oleh orang yang beriman, jumlah anak Rasulullah Muhammad saw dan silsilahnya dari pihak bapak dan ibunya.

4. Hikmah diutusnya para rasul.

Bagian ketiga dasar-dasar disiplin ilmu fikih(hukum) Mazhab Syafi'i. Pada bagian ini terdiri dari beberapa bagian antara lain:

1. Hukum seputar thaharah (bersuci) meliputi; pembagian air, wudhu, istinja', mandi dan tayammun.

2. Hukum seputar shalat meliputi shalat fardu serta waktu pelaksanaannya, syarat wajib dan syarat sah, rukun, sunnah (haiat dan $a b$ 'ad) dan yang membatalkan shalat. Disamping itu dijelaskan batasan aurat bagi laki-laki dan perempuan, tatacara pelaksanaan shalat apabila seseorang lupa atau ragu dalam shalat serta pelaksanaan sujud sahwi dan hukum shalat ied.

3. Hukum seputar kewajiban terhadap mayit; meliputi beberapa kewajiban terhadap mayit serta tatacara pelaksanaan shalat mayit dan penguburannya.

4. Hukum seputar zakat; meliputi harta yang wajib dizakati beserta syarat dan nishabnya serta orang-orang yang berhak memperoleh zakat.

5. Hukum seputar puasa; meliputi syarat wajib, fardhu, sunnah puasa 'serta hukum bagi yang orang yang berhubungan suami isteri pada siang hari sementara ia puasa. 
6. Hukum seputar haji dan umrah; meliputi syarat wajib haji, rukun haji dan umrah, wajib dan sunnah haji, hal-hal yang diharamkan bagi orang telah berihram, hukum apabila seseorang meninggalkan salah satu amalan haji serta tatacara pelaksanaan dam (denda).

\section{Terjemahan Teks Tauhid Naskah BAMDC}

Dengan nama Allah yang Maha Pengasih lagi maha Penyayang

\section{Sifat-sifat Wajib bagi Allah swt}

Setiap mukallaf wajib menghafal 20 sifat Allah swt.

S : (Sifat) apa yang wajib bagi Allah swt?

J : Wajib bagi Allah swt 20 sifat yaitu; Ada, Dahulu, Kekal, Berbeda Dengan Yang Baru, Berdiri Sendiri, Esa, Kuasa, Berkehendak, Mengetahui, Hidup, Mendengar, Melihat, Berbicara, dan keadaannya Maha Kuasa, Maha Berkehendak, Maha Mengetahui, Maha Hidup, Maha Mendengar, Maha Melihat dan Maha Berbicara.

Lawan dari sifat 20 yang wajib bagi Allah

S : (Sifat) apa yang mustahil bagi Allah swt?

J : Mustahil bagi Allah swt 20 sifat yaitu; Tiada, Baru, Binasa, Serupa dengan Yang Baru, Butuh kepada tempat tinggal atau atau yang membuat, Berbilang (lebih dari satu), Lemah, Terpaksa, Bodoh, Mati, Tuli, Buta, Bisu, dan keadaannya Maha Lemah, Maha Terpaksa, Maha Bodoh, Maha Mati, Maha Tuli, Maha Buta dan Maha Bisu.

S : (Sifat) apa yang jaiz (boleh) bagi Allah swt?

J : Boleh bagi Allah swt melakukan pekerjaan yang mumkin (untuk dilakukan) atau meninggalkannya.

\section{Sifat-sifat Wajib, Mustahil dan Jaiz bagi Rasul}

$\mathrm{S}: \quad$ (Sifat) apa yang wajib bagi rasul?

J : Wajib bagi rasul empat sifat yaitu jujur, amanah (terpercaya), menyampaikan dan cerdas.

$\mathrm{S}: \quad$ (Sifat) apa yang mustahil bagi rasul?

J: Mustahil bagi rasul empat sifat, yaitu; bohong, khianat, menyembunyikan dan bodoh.

S : (Sifat) apa yang jaiz (boleh) bagi rasul?

$\mathrm{J}$ : $\quad$ Boleh bagi mereka (para rasul) terjadinya prilaku manusia yang tidak mengurangi derajat mereka yang tinggi seperti sakit, makan, minum, tidur dan lain sebagainya.

\section{Rasul yang Wajib Diketahui}

S : Ada berapa jumlah rasul yang wajib diketahui?

J: Jumlah rasul yang wajib diketahui ada 25 nabi yang diutus yaitu; Adam, Idris, Nuh, Hud, Shalih, Ibrahim, Luth, Isma'il, Ishhaq, Ya'qub, Yusuf, Ayyub, Syu'aib, Musa, Harun, Dzu al-Kifli, Dawud, Sulaiman, Ilyas, Ilyasa', Yunus, Zakariyya, Yahya, Isa dan Muhammad 'alaih al-salatu wa al-salam.

S: Ada berapa jumlah anak junjungan kita Muhammad saw?

J : Jumlah anaknya ada tujuh 3 diantara laki-laki yaitu Abdullah, al-Qasim dan Ibrahim, Serta 4 perempuan Fatimah, Zainab, Ruqayyah dan Ummu Kaltsum dan kesemuanya dari istrinya Khadijah kecuali Ibrahim yang berasal dari istrinya Mariyah al-Qibtiyyah.

S : Apa nasab (garis keturunan) Muhammad saw dari pihak bapaknya?

J : Dialah Muhammad saw bin Abdullah bin Abd. Muttalib bin Hasyim bin Abd. Manaf bin Kilab yang terkenal dengan Hakim bin Murrah, bin Ka'ab bin Luay, bin Fihr bin Malik bin alNadhr bin Kinanah bin Khuzaimahi bin Mudrikah bin Ilyas bin Mudhar bin Nizar bin Ma'di bin 'Adnan yang dari bersambung nasabnya kepada Sayyidina Ismail as bin Ibrahim as.

S : Apa nasab (garis keturunan) Muhammad saw dari pihak ibunya?

J : DiaMuhammad saw bin Aminah binti Wahab bin Abdi Manaf bin Zuhrah bin Kilab yang terkenal dengan Hakim sebagaimana yang disebutkan pada nasab Bapaknya.

\section{Hikmah Diutusnya Para Rasul}

S : Apa hikmah diutusnya para rasul?

J: (Hikmah diutusnya para rasul) yaitu: untuk menolak perbuatan melampaui batas, agar manusia mengenal tuhannya, mengikuti kebenaran, menjauhi kebatilan, mengetahui kebaikan dari keburukan, dan mudharat dari manfaat, melaksankan perintah-perintah Allah serta menjauhi larangan-larangan-Nya sehingga (manusia) selamat di dunia dan akhirat. 


\section{Fungsi Naskah Bahan Ajar Madrasah Diniyah Campalagian}

Sebagaimana telah diketahui bahwa Kecamatan Campalagian merupakan salah satu pusat pendidikan Islam di Kabupaten Polewali Mandar.Hal ini ditandai dengan munculnya beberapa lembaga pendidikan Islam yang dipelopori oleh ulama-ulama setempat. Transformasi ajaran Islam di Campalagian melalui beberapa lembaga pendidikan Islam sangat besar.Hal ini terlihat dari kuantitas orang yang belajar di lembaga pendidikan tersebut. Mereka bukan saja berasal dari masyarakat Campalagian tapi juga banyak yang berdatangan dari daerah lain, bahkan dari luar wilayah Kabupaten Polewali Mandar.

Materi pembelajaran yang digunakan dalam transfer ilmu merujuk pada beberapa kitab kuning serta tulisan atau catatan guru. Tulisan atau catatan inilah melahirkan sebuah naskah pegangan bagi santri.Jenis naskah terdiri beberapa materi agama Islam seperti tauhid, fikih, akhlak serta catatan lainnya. Di antara ulama yang memiliki naskah antara lain; H. Muhammad Zeid (Mantan Qadhi Campalagian), H. Muhammadiyah (Mantan Khatib Mesjid Raya Campalagian), H. Muhammad Hasan serta beberapa ulama lain.

Salah satu naskah tersebut yaitu Naskah Bahan Ajar Madrasah Diniyah Campalagian (BAMDC). Naskah ini masih disimpan secara dengan baik oleh pemiliknya. Pada awalnya naskah itu yang ditulis disimpan dan dirawat dengan baik. Namun seiring dengan perjalanan waktu, naskah tersebut mengalami proses penuaan sehingga tidak menjamin kondisi fisik naskah masih layak baca. Ini terjadi akibat penyimpanan naskah tidak sesuai dengan standar penyimpanan naskah kuno.

NaskahBAMDC ini berisi pokok ajaran Islam berupa kumpulan hadis, serta disiplin ilmu tauhid dan fikih. Pokok bahasan inilah yang menjadi bahan ajar di Madrasah Diniyah Campalagian untuk ditransformasikan kepada peserta didik. Tujuan pembelajaran ini yaitu agar peserta didik memamahami dasar-dasar ajaran Islam berupa akidah (tauhid), hukum Islam yang meliputi ibadah sehari-hari (fikih) serta beberapa hadis Nabi saw. sebagai bekal bagi para peserta didik sebagai calon kader ulama.

Naskah BAMDC berfungsi sebagai bahan ajar pada lembaga pendidikan non formal yang ada di Kecamatan Campalagian Kabupaten Polewali Mandar yang sejak dulu terkenal sebagai pusat kegiatan agama di Propinsi Sulawesi Barat. Ini dapat dilihat dari jumlah madrasah, pesantren, majelis taklim maupun lembaga keagamaan lain yang tersebar diseluruh penjuru kabupaten ini. Begitupula Madrasah Diniyah di .kabupaten Polewali Mandar terdapat di hampir setiap kecamatan. Madrasah diniyah olehpenduduk setempat disebut dengan "Sikola Arab" (sekolah yang proses belajar mengajarnya menggunakan bahasa arab). Sekolah model inilah yang kemudian pada beberapa lokasi berubah menjadi Madrasah Diniyah Takmiliyah. Madrasah-madrasah tersebut mengajarkan tauhid, fikih, akhlak, Alquran, hadits dan Bahasa Arab.

Khusus di kecamatan Campalagian, pembelajaran lebih ditekankan pada pendalaman materi bahasa Arab berupa kaidah nahwudan sharaf, fikih, akidah serta akhlak. Ini bisa dilihat pada materi serta kitab-kitab yang diajarkan, misalnya bidang Bahasa Arab seperti; Sharaf Galappo, Awamil, Matn Aljurumiyah dan Syarahnya, Mutammimah Aljurumiyahserta Kawakib alDurriyyah, bidang Fikih seperti; Matn Saflnatunnajah dan Syarahnya (Kasyifah al-Saja), Fathul Qarib, Fathul Mu'in, Kifayatul Akhyar, Bidang Akidah seperti; Jawahir al-Kalamiyyah, Kifayatul Awwam dan Al-Sanusiyyah. Realitas ini berbeda dengan pembelajaran di daerah lainnya misalnya di Pambusuang yang juga menekankan materi Tasawuf dan Tarikat.

Materi Akidah yang diajarkan tersebut bersumber dari beberapa kitab rujukan serta naskah. Pada Naskah BAMDC materi akidah meliputi pengenalan terhadap sifat-sifat wajib, mustahil danjaizb\&gi Allah swt., sifat-sifat wajib, mustahil danj'a/zbagi RasulRasul (utusan) Allah swt., serta hikmah diutusnya Rasul-Rasul Allah swt.

\section{PENUTUP}

Dari hasil hasil analisis terhadap teks tauhid naskahBAMDC, dapat ditarikkesimpulan sebagai berikut:

1. Naskah BAMDCditulis dalam bentuk prosa. Kondisi naskah masih baik namun beberapa bagian dari naskah terdapat gejala-gejala corrupt (robek).

2. Naskah BAMDC berisi dasar-dasar ajaran Islam meliputi kumpulan-kumpulan hadis, ajaran akidah (tauhid) dan fikih (hukum).

3. Pada penulisan Naskah BAMDC terdapat 15 kesalahan yaitu; ablesie 7 data, fantes gramatical 3 data, lacunae 2 data, apokope 2 data dan interpolation 1 data. 
4. Naskah BAMDC berperan sebagai bahan ajar di Madrasah Diniyah Campalagian sebagai bentuk pengenalan dasar-dasar ajaran agama kepada peserta didik.

\section{DAFTAR PUSTAKA}

Baried, Siti. Barorah. et. al. 1994. Pengantar Teori Filologi. Yoyakarta: Badan Penelitian dan dan Publikasi Fakultas Seksi Filologi Fakultas Sastra Universitas Gadjah Mada

Lubis, Nabilah. 2007. Naskah, Teks dan Metodologi Penelitian Filologi. Cet. IV; Jakarta PuslitbangLekturKeagamaan Badan Litbang dan Diklat Departemen Agama RI.

Nababan, Rudolf. 2008. Teori Menerjemah Bahasa Inggris. Cet. HI; Yogyakarta: Pelajar.

Naskah Bahan Ajar Madrasah Diniyah Campalagian.. Manuskrip. Campalagian: Disimpan oleh H. Mukhtar Hasan.

Pradotokusumo, Partini Sardjono. 2001. Pengkajian Sastra.. Cet. I; Bandung: Wacana.

Seksi Mapenda Kantor Kemenag Kabupaten Polewali Mandar tahun 2010.

Wawancara dengan H. Mukhtar Hasan tanggal 16 September 2010 di Campalagian. 